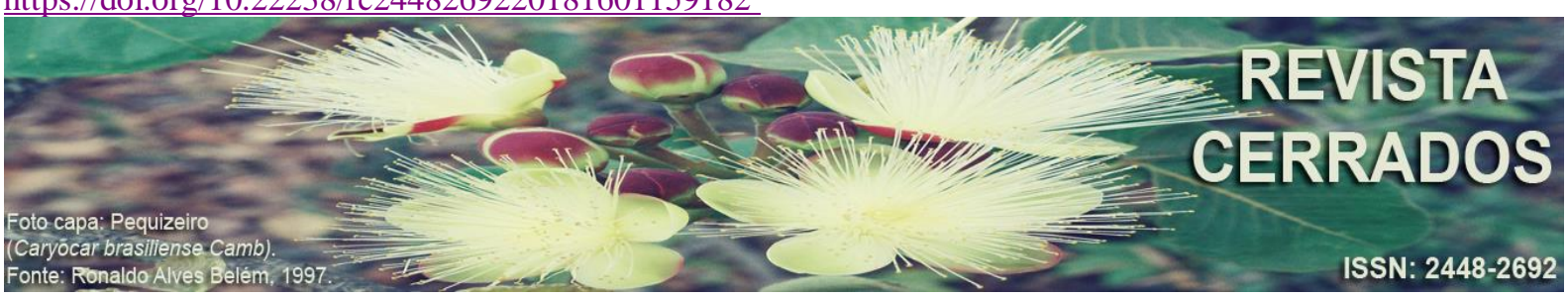

\title{
A LOGÍSTICA URBANA NA PRODUÇÃO DO ESPAÇO
}

\section{URBAN LOGISTICS IN THE PRODUCTION OF SPACE}

\section{LA LOGÍSTICA URBANA EN LA PRODUCCIÓN DEL ESPACIO}

\author{
Fander de Oliveira Silva \\ Universidade Federal de Uberlândia - UFU \\ E-mail:<fanderoliveira@hotmail.com>. \\ William Rodrigues Ferreira \\ Universidade Federal de Uberlândia - UFU \\ E-mail: 〈wferreira@ufu.br>.
}

\begin{abstract}
RESUMO
Atualmente, embora o conceito de produção extrapole a materialidade, a categoria central que o tem fundamentado é a reprodução do modo de vida, sendo o trabalho um fator de extrema importância na condução das práticas de territorialização e desterritorilização, deslocando os fixos, fluxos e suas relações espaciais, ao passo que lhe escapa a reprodução do espaço e do capital. Dessa forma, este trabalho tem por objetivo compreender as relações do espaço geográfico, do território e das redes de transportes na proposta da Logística, chegando ao ponto de partida da Geografia dos Transportes caracterizado por análises dos sistemas de transporte que redundam na contribuição para as transformações territoriais nos seus eixos cardeais: a produção, reprodução, estruturação e reestruturação. Nesse contexto, a atuação do Poder Público e do empresariado no território brasileiro tem se pautado cada vez mais na racionalidade e na eficácia dos fluxos materiais, de modo que a moderna Logística surge como uma questão-chave para o desenvolvimento. Em uma macroeconomia em que a velocidade e as especificidades do produto têm vasta relevância, bem como a capacidade de conjugar o tempo, distribuir espaços de produção e abastecimento no quadro da cadeia de suprimentos (supply chains), percebe-se que a Logística evolui, tornando-se alicerce central na geração de vantagens competitivas.
\end{abstract}

Palavras-chave: Logística Urbana. Produção do Espaço. Geografia dos Transportes. Uberlândia.

\section{ABSTRACT}

Nowadays, although the concept of production goes beyond materiality, the central category that supports it is the reproduction of the way of life, with work being a factor of extreme 
SILVA, F. O.; FERREIRA, W. R.

A logística urbana na produção do espaço

importance in the conduct of territorialization and deterritorilization practices, displacing the fixed, flows and their Spatial relations, while it escapes the reproduction of space and capital. The purpose of this paper is to understand the relationships between geographic space, territory and transport networks in the Logistics proposal, reaching the point of departure of Transport Geography characterized by analyzes of transport systems that contribute to the transformations In the cardinal axes: production, reproduction, structuring and restructuring. In this context, the performance of the Public Power and business in the Brazilian territory has been increasingly based on the rationality and effectiveness of material flows, so that modern Logistics emerges as a key issue for development. In a macroeconomy in which product speeds and specificities have great relevance, as well as the ability to combine time, distribute production and supply spaces within the supply chain, it is noticed that Logistics evolves, Becoming central to the generation of competitive advantages.

Key-words: Urban Logistics. Production of Space. Geography of Transportation. Uberlandia.

\section{RESUMEN}

En la actualidad, aunque el concepto de producción extrapole la materialidad, la categoría central que lo ha fundamentado es la reproducción del modo de vida, siendo el trabajo un factor de extrema importancia en la conducción de las prácticas de territorialización y desterritorilización, desplazando los fijos, flujos y sus relaciones espaciales, mientras que le escapa la reproducción del espacio y del capital. De esta forma, este trabajo tiene por objetivo comprender las relaciones del espacio geográfico, del territorio y de las redes de transporte en la propuesta de la Logística, llegando al punto de partida de la Geografía de los Transportes caracterizado por análisis de los sistemas de transporte que redundan en la contribución a las transformaciones territoriales en sus ejes cardenales: la producción, reproducción, estructuración y reestructuración. En este contexto, la actuación del Poder Público y del empresariado en el territorio brasileño se ha guiado cada vez más en la racionalidad y la eficacia de los flujos materiales, de modo que la moderna Logística surge como una cuestión clave para el desarrollo. En una macroeconomía en la que la velocidad y las especificidades del producto tienen una gran relevancia, así como la capacidad de conjugar el tiempo, distribuir espacios de producción y abastecimiento en la cadena de suministros, se percibe que la Logística evoluciona, convirtiéndose en el fundamento central en la generación de ventajas competitivas.

Palabras clave: Logística Urbana. Producción del espacio. Geografía de los Transportes. Uberlandia.

\section{INTRODUÇÃOO}

O mundo, após a segunda metade do século XX, depois da Segunda Guerra Mundial, ingressou em uma etapa de profundas evoluções no campo tecnológico estimulado principalmente pela convergência entre o conhecimento científico e a produção, caracterizando por Milton Santos (1999) por período técnico-científico-informacional. Com 
SILVA, F. O; FERREIRA, W. R.

A logística urbana na produção do espaço

os avanços empregados passou-se a integrar e valorizar principalmente a produção do espaço urbano.

Nesta situação o Poder Público garante um importante papel por ter possibilidade de estabelecer os seus marcos jurídicos de uso e ocupação do solo, de taxar a propriedade fundiária, as edificações e atividades urbanas, de produzir condições para outros sujeitos produtores, de promover o setor imobiliário investindo em imóveis residenciais em determinados locais para determinadas pessoas, controlar a expansão do perímetro urbano, interferir na implantação das instalações industriais, entre tantos outros.

Revela-se assim a produção das cidades um processo real, amplo e profundo como um conjunto de ações, relações e modelos que vão formalizar a cidade e sua dimensão política, social, econômica. Neste cenário, as cadeias logísticas têm papel protagonista na produção do espaço urbano, impactando a política, a economia e até mesmo a cultura de consumo da sociedade.

Apesar de sua importância, as cadeias logísticas também contribuem para o surgimento e/ou intensificação de inúmeros problemas recorrentes principalmente nas áreas centrais, como congestionamentos, poluição ambiental, aumento dos ruídos e acidentes de trânsito. Quanto à atuação do Poder Público e das empresas no território, ela tem se apoiado cada vez mais na racionalidade e eficácia dos fluxos materiais e imateriais, de modo que a moderna Logística Urbana surge como uma questão-chave para o desenvolvimento socioeconômico.

Assim, o objetivo deste trabalho consiste em compreender as relações do espaço geográfico, do território e das redes de transportes na proposta da Logística, partindo da Geografia dos Transportes que caracteriza os sistemas de transporte que redundam na contribuição das transformações territoriais: a produção, reprodução, estruturação e reestruturação.

Para o atingimento do objetivo central, a metodologia utilizada consistiu em um denso levantamento bibliográfico, que permitiu a partir da Geografia diagnosticar a cidade em sua perspectiva de produção e reprodução, alicerce para futuras interpretações e desenhos dos seus horizontes de possibilidades.

\section{CONCEPÇÕES E PRÁTICAS DA PRODUÇÃO DO ESPAÇO}


SILVA, F. O; FERREIRA, W. R.

A logística urbana na produção do espaço

Tradicionalmente carregado de singulares e mutáveis significados, o conceito de espaço cada vez mais tem se fragmentado na natureza das ciências, desmembrando-se em sentidos geográfico, social ou histórico, entre outros. Em meio às indagações sobre a reprodução das relações do homem no espaço, isto é, sua organização no ambiente em que se insere, encontram-se as reflexões de Lefevre (1991), Corrêa (1982), Moreira (1982), Santos (1999) e Harvey (2002), que levantam as seguintes questões: O que é o espaço? Como se produz o espaço? Como e por que se dá a sua produção?

As respostas apresentam algumas características distintas, mas deve-se considerar que na Geografia o espaço não é apenas passível de classificação e descrição, mas também fonte para uma discussão múltipla e rica. Diante disso, adotaremos a concepção de Milton Santos (2002) por resgatar conceitos, categorias e proposições de outros autores nesse debate, estabelecendo uma teoria geográfica social crítica ao entender que o espaço geográfico é

“... formado por um conjunto indissociável, solidário e também contraditório, de sistemas de objetos e sistemas de ações, não considerados isoladamente, mas como o quadro único no qual a história se dá.” (SANTOS, 2002, p.63).

A natureza é a origem: ela fornece a matéria a ser transformada em produtos pela ação humana através da técnica. Essa seria uma das principais formas de relação entre o homem e a natureza, pela qual se realiza a vida na criação e produção do espaço (SANTOS, 2004, p.33). Nesse sentido, o espaço era considerado como vazio, passivo ou "produto" que se esgotava quando trocado e consumido. Essa concepção só veio a se enquadrar como categoria de análise nas discussões científicas com o advento da urbanização. Agora, o espaço passa a ser compreendido como indissociável dos seus produtos e ações e, como tal, não pode mais ser analisado categoricamente separado, sob o risco de perder a sua essência.

À medida que as relações campo-cidade se modificavam em direção à escala mundial e a urbis $^{1}$ se difundia na sua explosão generalizada, o espaço ganhava novos enfoques científicos. Passou-se, então, a indagar qual o lugar da urbanização, quais os seus produtos, quem dele se apropria e desapropria e em quais circunstâncias e tempo. Agora a

\footnotetext{
${ }^{1}$ Segundo o dicionário Etimológico Nova Fronteira da Língua Portuguesa, de autoria de Cunha (1982), a data provável do vocábulo 'cidade' gira em torno do século XIII, sendo originário do latim civitas-âtis. Embora esse dicionário não registre a palavra urbano, apresenta o vocábulo urbe, indicando o século XX como datação para sua inclusão na língua portuguesa. Urbe tem o sentido de cidade e deriva da palavra latina ubs, urbis. Curioso é notar que as palavras suburbano e urbanidade são usadas em português desde o século XVI e que a palavra urbanista antecede o termo urbanismo, já que a primeira é de 1874, enquanto que o segundo é do século XX. (CUNHA, 1982, p. 182-804).
} 
SILVA, F. O; FERREIRA, W. R.

A logística urbana na produção do espaço

produção do espaço teria sentido a partir da ação humana, na qual estariam implicados não apenas produtos, mas também seus atores e suas realizações.

Atualmente, embora o conceito de produção extrapole a materialidade, a categoria central que o tem fundamentado é a reprodução do modo de vida, sendo o trabalho um fator de extrema importância na condução das práticas de territorialização e desterritorilização, deslocando os fixos, fluxos e suas relações espaciais, ao passo que lhe escapa a reprodução do espaço e do capital.

Ainda que não haja uma resposta imediata ou mesmo exata sobre essas relações, o modo de produção tem se projetado no espaço sem a capacidade de, por si só, ordenar a extensão espacial, destinada a se reproduzir ao ritmo da globalização. Nas palavras de Lefebvre (1991):

\begin{abstract}
"De início, houve utilização do espaço existente, por exemplo, das vias aquáticas (canais, rios, mares), depois das estradas; na seqüência, construção de estradas de ferro, para continuar pelas auto-estradas e pelos aeroportos. Nenhum meio de transporte no espaço desapareceu inteiramente, nem a caminhada, nem o cavalo, nem a bicicleta etc. Contudo, um espaço novo se constituiu no século XX, à escala mundial; sua produção, não terminada, continua. O novo modo de produção (a sociedade nova) se apropria, ou seja, organiza para seus fins, o espaço preexistente, modelado anteriormente." (LEFEBVRE, 1991, p.19).
\end{abstract}

Dito de outro modo, inputs ${ }^{2}$ são inseridos lentamente em uma espacialidade e se apropriam do espaço modelado anteriormente, ou o organizam ou, ainda, o subvertem para seus fins, como é o caso atual da inserção do Veículo Urbano de Carga (VUC) nos grandes centros urbanos do Brasil. A organização precedente da movimentação de bens e mercadorias, antes feita basicamente por caminhões de eixo simples (com capacidade de até 6 toneladas, peso bruto máximo de 16 toneladas e comprimento máximo de 14 metros) e também por caminhões tipo truck, que têm eixo duplo (com capacidade entre 10 e 14 toneladas, peso bruto máximo de 23 toneladas e comprimento também de 14 metros), é induzida a uma desintegração e o modo de produção desenvolve para si uma nova reorganização do espaço. Esses recursos, historicamente utilizados em razão da capacidade e do custo, são substituídos nos centros urbanos pelo VUC, que se torna tendência nos deslocamentos diários de cargas. Tal substituição se dá, inicialmente, por fatores econômicos, mas depois passa a ser

\footnotetext{
${ }^{2}$ Input é uma expressão da língua inglesa que significa entrada. O termo é muito utilizado na área da Tecnologia da Informação (TI), como também em diversas outras áreas das ciências humanas, exatas, biológicas etc.

Revista Cerrados, Montes Claros/MG, v.16, n. 1, p. 159-182, jan./jun.-2018
} 
SILVA, F. O; FERREIRA, W. R.

A logística urbana na produção do espaço

determinada também pelas condições do sistema viário e de circulação dos centros das cidades, bem como pela ideia de qualidade de vida associada ao conceito de sustentabilidade.

O modo de produção induz a regulamentação das vias de tráfego urbano já existentes; criam-se, em alguns casos, vias exclusivas e/ou áreas específicas para a circulação de cargas. A partir daí, insere-se a sociedade em um novo contexto espacial, pautado em modelos mundiais: a carga passa a ser valorizada e incorporada tanto nos centros urbanos quanto nos anéis rodoviários, que expandirão a cidade, alimentando, por fim, um círculo espacial de produção.

Tal "organização" e produção espacial servem, ao mesmo tempo, ao Poder Público e ao capitalismo. Ao primeiro, por otimizar e facilitar sua gestão e produção de espaços. E ao segundo, por permitir que, através das corporações, se reinventem, em detrimento de determinadas classes sociais e espaços, os seus investimentos e modelos espaciais. Diante da magnitude e profundidade das concepções sobre o espaço, esmiuçaremos alguns conceitos balizadores da Geografia, tais como território, fixos e fluxos, redes e circuitos espaciais produtivos, a fim de possibilitar a construção dos pressupostos teóricos e metodológicos que nos permitirão formular e compreender a Geografia dos Transportes.

Do conceito de espaço geográfico já abordado, tomamos como norte a necessidade de considerar os produtos e as ações de forma indissociável no processo contínuo pelo qual a sociedade transforma a natureza, produzindo e reproduzindo o espaço através do trabalho. Isto nos faz levar em conta as relações entre os sujeitos (sociedade em geral, Poder Público e corporações) que, por meio dos seus direitos ou "poderes", influenciam a produção do espaço. Daí surge o território: fração e resultado das interações dos sujeitos no meio em que se inserem.

Dessa forma, como observaremos adiante, o espaço geográfico, o território e as redes de transportes serão fundamentais para a proposta da Geografia dos Transportes e para a análise da questão logística, já que são elementos cruciais em ambos os assuntos. As diferentes definições e os sentidos de território variam em função de uma abordagem jurídica, sociocultural e mesmo afetiva. Sua problematização se ancora em aspectos vinculados às interações que a sociedade estabelece com a natureza, mediadas por mecanismos de apropriação, dominação, ocupação ou posse de uma parte do espaço.

O termo território deriva do latim territorium, que explicita sua ligação com a terra, mais precisamente uma fração de terra apropriada, onde se constroem relações tanto de 
SILVA, F. O; FERREIRA, W. R.

A logística urbana na produção do espaço

base materialista quanto abstrata. Embora não haja consenso sobre essa etimologia, vale ressaltar que, direta ou indiretamente, designa-se por território uma porção da natureza delimitada na superfície, portanto, quinhão do espaço, sobre o qual uma sociedade reivindica e garante a todos, ou a parte de seus membros, direitos estáveis de acesso, controle e uso, com respeito à totalidade ou parte dos recursos que aí se encontram e que esse grupo social deseja e é capaz de explorar. (GODELIER apud HAESBAERT, 2002, p. 56).

São vários os autores da Geografia que se dedicam à etimologia e à filosofia do território. Dentre as limitações e diferenças de cada um deles, a proposta de Claude Raffestin (1993, p.144) parece ser a mais consensual nas discussões sobre as dinâmicas territoriais. Para o autor, o espaço é “... de certa forma, 'dado' como se fosse uma matéria-prima. Preexiste a qualquer ação. 'Local' de possibilidades, é a realidade material preexistente a qualquer conhecimento e a qualquer prática." Uma das principais proposições do autor sobre o território se refere a sua indissociabilidade do poder. Disso podemos tomar como princípio que toda relação de poder estabelecida no espaço produz um território, com intensidade e forma de ação em diferentes escalas e profundidades.

A tendência global, homogeneizante e fragmentadora do capital, utiliza-se de tal poder para exigir a organização espacial de modo a gerar as condições de fluidez para seus fixos (pontos de serviços, pontos produtivos, casas de negócios, hospitais, escolas, espaços de lazer) e fluxos (técnica, circulação, distribuição, consumo, política, informação), promovendo a aceleração da circulação de pessoas, bens, mercadorias, serviços e informações. Nessas circunstâncias, só a produção não basta. Para Silveira (2011), é necessário colocá-la em movimento, pois isso passou a reger o próprio ato produtivo.

Com as especializações territoriais, efeito da ampliação do domínio das corporações, os territórios tendem a se modificar em menos tempo e continuamente.

Quanto há mais imperativo de circulação do capital, mais há imperativo de expansão dos fixos e dos fluxos de transportes, armazenagem e de comunicações. Portanto, é através da produção e da circulação que o espaço geográfico é produzido. (SILVEIRA, 2011, p. 46.).

Nesse sentido, o tempo, enquanto condição da globalização, é a medida de valor que exige a superação dos obstáculos espaciais para expandir a acumulação do capital, o equilíbrio e a especialização do território. Uma vez que a circulação é o vetor fundamental do processo social e econômico, o território é equipado para facilitar a mobilidade necessária à 
SILVA, F. O; FERREIRA, W. R.

A logística urbana na produção do espaço

economia mundial dos fluxos. Para isso, o modo capitalista de produção requer e fomenta formas baratas e rápidas de comunicação e transporte (HARVEY, 2006).

Esse status ocupado pela circulação é capaz de romper equilíbrios preexistentes e alterar a configuração territorial local e regional, pois atender à crescente necessidade de movimento, característica do período técnico- científico- informacional, só é possível com o respectivo incremento dos capitais fixos e constantes (SANTOS, 1996). Ao mesmo tempo, devem-se considerar e acrescentar as interações espaciais ${ }^{3}$, que precisam ser flexíveis para superar as restrições físicas e abstratas do território e proporcionar maior fluidez na circulação, contemplando a velocidade, o conforto, a acessibilidade, a segurança, a frequência, o custo ótimo e a informação.

É nesse sentido que a Logística, como sistema arterial, vai eliminar (ou pelo menos minimizar) as descontinuidades territoriais. Chegamos ao ponto de partida desse ramo geográfico caracterizado por análises dos sistemas de transporte que redundam na contribuição para as transformações territoriais nos seus eixos cardeais: a produção, reprodução, estruturação e reestruturação.

Entre os territórios e a mobilidade dos seus atores é merecida a existência de uma disciplina que faça uma investigação específica; daí a Geografia dos Transportes. Tradicionalmente amparada em estudos clássicos sobre o ordenamento territorial - Weber (1929), Isard (1956), Christaller (1966), Perroux (1967), Myrdal (1968), Taaffe \& Gauthier (1973), Pons e Reynés (2004) -, ela tem se mantido no domínio das ciências sociais, embora também incorpore ou influencie metodologias e concepções de outras ciências, como Administração, Economia, Engenharias, Arquitetura e Urbanismo. Contudo, a Geografia dos Transportes não se desmembrou dos demais ramos da Geografia, em especial a Humana, de onde surgiu.

\footnotetext{
"Em sus orígenes, como subdisciplina diferenciable em el conjunto de Geografía Humana, la Geografía del Transporte se concibío como um campo de estúdio eminentemente funcionalista que centro su atención em la circulación de personas y mercancias y em como esta circulacíon guardaba relacíon com la ubicación em el espacio de los asentamientos humanos y los centros productivos, tejiendo sobre él redes y orgnizándolo de forma que se minimizaran los costes derivados de los desplazamientos.” (BEY, PONS E REYNÉS, 2011, p.95).
}

\footnotetext{
${ }^{3}$ As interações espaciais são representadas por um amplo e complexo conjunto de deslocamentos de pessoas, de mercadorias, de capitais e de informações sobre o espaço geográfico, podendo variar em sua intensidade e em sua frequência, dependendo da distância e direção. (CORRÊA, 1997, p.279).
} 
SILVA, F. O.; FERREIRA, W. R.

A logística urbana na produção do espaço

Trata-se de um dos campos da Geografia com maior diversidade de pesquisas, tanto teórico-metodológicas quanto empíricas. Suas temáticas são ampliadas à medida que as relações espaciais se tornam mais complexas em um mundo de questionamentos e investigações. Tem por objetivo estudar os sistemas de transportes e seus impactos (HOYLE; KNOWLES, 2000 apud PONS; REYNÉS, 2004), ou seja, as interconexões entre os meios e as vias de transporte, o movimento e seus modelos espaciais, a estrutura de rede e as interações que proporcionam.

Devido à evolução dos movimentos mercantis após a Segunda Guerra Mundial, quer no âmbito da circulação quer no ordenamento territorial, a complexidade das interações espaciais por meio do transporte, isto é, as redes, tem se ampliado nos espaços urbanos, sobretudo nas últimas décadas. Ao passo que se organizam, mediante ações do Poder Público e das grandes corporações, para extrapolarem as barreiras locais, regionais e se tornarem globais, as redes de transporte se submetem à lógica do capital, tornando-se engrenagens dos circuitos espaciais de produção ${ }^{4}$ na medida em que ampliam a divisão territorial do trabalho.

Diante do exposto, fica evidente que na chamada "globalização" existe uma pluralidade de concepções, métodos e temáticas, destacando-se a interdisciplinaridade de enfoques. Na Geografia dos Transportes, a expansão e a modernização do território são caracterizadas pelo aprofundamento da divisão territorial do trabalho e das próprias redes de transportes, motivo pelo qual os conceitos de "circuito espacial de produção" tornam-se fundamentais para alicerçarmos o entendimento sobre estruturação, função e uso dos territórios.

\section{ESPACIALIDADES E TOPOLOGIAS DOS CIRCUITOS ESPACIAIS PRODUTIVOS}

A atual conjuntura que os sistemas de transportes e comunicação estão desenvolvendo tem otimizado cada vez mais a transposição de distâncias em um menor intervalo de tempo e com menos custos, proporcionando mudanças importantes na produção e gestão do território. Incontestavelmente, os dados empíricos sobre a nossa sociedade são argumentos conclusivos da desigualdade e também da diversidade, revelando a existência de

\footnotetext{
${ }^{4}$ Nessa perspectiva, os circuitos espaciais de produção pressupõem a circulação de matéria no encadeamento das instâncias geograficamente separadas da produção, distribuição, troca e consumo, de um determinado produto, num movimento permanente. (CASTILLO; FREDERICO, 2010, p. 464).
} 
SILVA, F. O; FERREIRA, W. R.

A logística urbana na produção do espaço

pelo menos dois tipos de espaços: o "dos que mandam" e o "dos que obedecem", marcados pela competição e não pela solidariedade. Nessa oposição, as $\operatorname{rugosidades}^{5}$ não são apenas marcos memoriais de uma globalização construída, mas sim legítimas diferenças sociais, econômicas, políticas e ambientais que não foram e não são respeitadas.

Essa estrutura, segundo Santos (1999), está inserida em um contexto de transição do meio técnico para o técnico-científico-informacinal, em que a circulação e a informação passam a ser decisivas para o sistema de produção e mais-valia. Assim, o território é palco de profundas reestruturações que se manifestam de formas e em tempos desiguais, nem sempre apresentando respostas imediatas, como já discutimos. Em contrapartida, há aqueles territórios que se adéquam à lógica dos circuitos espaciais produtivos da economia urbana com maior facilidade e velocidade.

Desde a década de 1970 até os dias atuais, devido aos arranjos e redefinições do território em razão do desenvolvimento dos sistemas de transporte e comunicação, podemos identificar a incorporação de territórios antes desvalorizados como vazios, opacos e limitados a atividades locais à lógica regional e mesmo global, em muitos casos. Esse fato tem contribuído bastante para que as etapas do processo de produção pudessem articular tempo e espaço por meio da fluidez das redes.

A fluidez contemporânea é baseada nas redes técnicas, que são um dos suportes da competitividade. Daí a busca voraz de ainda mais fluidez, levando à procura de novas técnicas ainda mais eficazes. A fluidez é ao mesmo tempo, uma causa, uma condição e um resultado (SANTOS, 1999, p. 218).

A voracidade na busca por técnicas mais eficazes induz o favorecimento dos territórios e sua valorização de modo sincronizado com as redes de transportes, que são um dos pilotos na geração de impactos no contexto intraurbano, pois distribuem a produção e dão mobilidade à sociedade.

Esses processos se intensificam continuamente e as redes têm se cristalizado como objeto de estudo de inúmeras ciências. Para Raffestin (1993. p.156), uma rede é "um sistema de linhas que desenham tramas. Uma rede pode ser abstrata ou concreta, invisível ou visível". Castells (2003, P.566) corrobora essa afirmação, acrescentando que se trata de "um

\footnotetext{
5 A noção de 'rugosidades' complementa a concepção de que a produção do espaço é, ao mesmo tempo, construção e destruição de formas e funções sociais dos lugares. Ou seja, a (des) construção do espaço não se refere apenas à destruição e à construção de objetos fixos, mas também às relações que os unem em combinações distintas ao longo do tempo. Para Santos (1980, p. 138), as rugosidades nos oferecem, mesmo sem tradução imediata, restos de uma divisão internacional do trabalho.

Revista Cerrados, Montes Claros/MG, v.16, n. 1, p. 159-182, jan./jun.-2018
} 
SILVA, F. O; FERREIRA, W. R.

A logística urbana na produção do espaço

conjunto de nós interconectados". Portanto, as redes são compreendidas não somente em suas dimensões técnicas, mas também abstratas, remetendo a elementos sociais e econômicos.

Sendo assim, todo o processo de produção, reestruturação, modernização da logística e a constante redefinição das redes e de seus respectivos nós se referem à dinâmica da estrutura espacial e temporal na qual a sociedade está inserida (HARVEY, 1992) e que contribui para a perpetuação desse modelo de vida baseado na velocidade das ações, ou seja, na mecanização das atividades em função do tempo de execução. É o que Santos (2002) define como "frenesi da velocidade".

Em síntese, desvendar o conteúdo das redes, a arquitetura das interações e dos circuitos espaciais da produção possibilita compreender as dinâmicas e o próprio uso do território mediante as atividades econômicas que se articulam em diferentes etapas do processo de produção (BOMTEMPO, 2011).

As interações espaciais são qualificadas por Corrêa (1997) como "componente do espaço geográfico", como um amplo e diverso deslocamento multidirecional de mercadorias, pessoas, capitais e informações, com diversas densidades de fluxos e velocidades. Desse modo, as redes de transportes são determinantes para a produtividade do trabalho e para o desenvolvimento socioeconômico, assim como para a condução de um (re) ordenamento territorial mais justo no que se refere à acessibilidade e qualidade de vida.

As especificidades de tais interações não serão explanadas neste estudo. No entanto, a leitura do território pela via dos circuitos espaciais de produção no período de globalização é uma das maneiras de entender as dinâmicas em suas diversas escalas e profundidades. Nesse sentido, adotaremos os conceitos de circuito espacial de produção e a teoria dos dois circuitos da economia urbana -superior e inferior (SANTOS, 2004) - para uma breve síntese da dinâmica territorial das cidades médias, como é o caso de Uberlândia.

Em um mundo fragmentado em diversos subespaços especializados numa lógica global, precisamos falar em circuitos espaciais de produção, que podem ser entendidos, de acordo com Santos (2004), nas diversas etapas pelas quais passariam um produto, desde o começo de sua criação até chegar ao consumidor final.

A distância cada vez maior entre os locais de produção e os de consumo torna mais complexa a forma de se produzir e distribuir, confirmando a centralidade dos movimentos no termo "produtivo". Nas palavras de Moraes (1985, p.4), "discutir os circuitos 
SILVA, F. O.; FERREIRA, W. R.

A logística urbana na produção do espaço

espaciais da produção é discutir a espacialidade da produção-distribuição-troca-consumo como movimento circular constante.

Baseados em Marx (2011), chegamos à conclusão de que a produção, a distribuição, a troca e o consumo não são elementos idênticos, mas compõem uma mesma totalidade. Isto é, para que haja a produção deve-se pensar no consumo, visto que aquela não subsiste sem este e vice-versa; a distribuição também decorre do processo de produção e a troca corresponde ao movimento de circulação em geral. Há, portanto, uma interdependência entre as etapas para construir uma mesma unidade.

Assim, é possível afirmar que a ordem promulgada pelos circuitos espaciais produtivos certamente vai impor, ou pelo menos induzir, a espacialização da produção, que, através da divisão territorial do trabalho, promoverá uma dispersão geográfica das atividades, fomentando "forças de concentração" (ARROYO, 2012, p.24). Dito de outra forma, a especialização em uma determinada produção, característica dos territórios, é resultado de um jogo combinado das indústrias, que se apropriam das regras de mercado vigentes e estabelecem suas próprias organizações e funções. Em consonância, fundam-se os círculos espaciais de cooperação ${ }^{6}$, que pressupõe a comunicação baseada na transferência de ordens, informações e capitais (fluxos imateriais), garantindo os padrões e níveis desejáveis para articulação dos fixos dispersos, dos territórios descontínuos, a fim de unificá-los através de comandos.

Logo, a configuração dos circuitos de produção e círculos de cooperação está sujeita ao uso do território, representado pelos fluxos e fixos, à divisão internacional do trabalho e às relações que se estabelecem entre os agentes hegemônicos e não hegemônicos. $\mathrm{O}$ território é, então, orientado por projetos cujos olhares têm finalidades objetivas, prédeterminadas e indiferentes aos demais fatores, gerando usos e movimentos variados.

A título de exemplo, ressalte-se que Alemanha, França, EUA e Japão acolhem áreas de especialização no circuito espacial produtivo de veículos automotores do mundo, com empresas como Volkswagen, BMW, Renault, GM, Ford, Toyota, Honda, Suzuki e Mitsubishi. Embora apresentem características diferentes entre si quanto ao uso do território, da tecnologia, da informação, do capital, do trabalho e das redes de transportes, todas

\footnotetext{
${ }^{6}$ Constituem a orientação técnica que vem pelas empresas e instituições, as informações e ordens repassadas, sobretudo, pelas grandes multinacionais, o financiamento emitido pelos grandes agentes financeiros e a orientação macroeconômica das políticas governamentais (BOTELHO, 2010, p. 51).

Revista Cerrados, Montes Claros/MG, v.16, n. 1, p. 159-182, jan./jun.-2018
} 
SILVA, F. O; FERREIRA, W. R.

A logística urbana na produção do espaço

funcionam de maneira complementar, concorrente e interdependente, destacando-se as conexões pelos circuitos superior e inferior.

Cunhada por Milton Santos na década de $1960^{7}$, a teoria dos circuitos da economia urbana busca compreender o funcionamento das cidades dos países subdesenvolvidos, como o Brasil, a partir de dois subsistemas urbanos: o circuito superior, que inclui grandes corporações, bancos e empresas de tecnologia de ponta; e o circuito inferior, que abrange pequenas empresas, caracterizadas pelo uso intensivo de mão de obra e pela habilidade de se criar e recriar com pouco capital.

A sociedade nas cidades brasileiras, independentemente de sua hierarquia socioeconômica, possui necessidades permanentes e formas peculiares de produção, distribuição, trocas, consumo e uso capazes de gerar materialidades distintas e visíveis. Nesse contexto, os dois circuitos mencionados se relacionam intimamente a partir da complementaridade, subordinação e concorrência. As cidades, então, fomentam ambos os circuitos de produção da perspectiva miltoniana.

Chamaremos de espaços luminosos aqueles que mais acumulam densidades técnicas e informacionais, ficando assim mais aptos a atrair atividades com maior conteúdo em capital, tecnologia e organização. Por oposição, os subespaços onde tais características estão ausentes seriam os espaços opacos. (SANTOS, 2002, p. 264).

A origem desses circuitos está na modernização tecnológica, que confere aos países ditos desenvolvidos o poder de criar, concentrar, distribuir e impor suas novas técnicas ao restante do mundo, que, por sua vez, de acordo com suas singularidades, assimila e concretiza as novidades em uma estrutura de réplica.

Cientes do poder das corporações do circuito superior e de sua influência no que chamamos de circuito espacial produtivo, é necessário captar as interferências delas sobre o uso e a gestão do território, a fim de assegurar também a qualidade de vida, o bem-estar social. Dado que os interesses e ações do Poder Público se submetem às grandes empresas, são os circuitos espaciais produtivos que dominarão e (re) produzirão o território, promovendo níveis de complexidade e eficácia territorial. Tais circuitos podem ser

\footnotetext{
${ }^{7}$ Há vários artigos de Milton Santos publicados nas décadas de 1960 e 1970 sobre o tema. No entanto, é no livro "Espaço Dividido: os dois circuitos da economia urbana" que a teoria está sistematizada. Obra publicada primeiramente em francês: SANTOS, Milton. L'espace partagé. Les deux circuits de l'esconomie urbaine dês pays sous-développés. Paris, M-Th Génin. Librairies Techniques, 1975. A primeira edição em português é de 1979.
} 
SILVA, F. O; FERREIRA, W. R.

A logística urbana na produção do espaço

equilibrados, conexos e desenvolvimentistas nas diferentes escalas, como também desarmônicos e desequilibrados, polarizando o território e, concomitantemente, incrementando as desigualdades sociopolíticas, culturais e econômicas.

Pressupondo a necessidade de investigação, nos cabe reconhecer as indicações metodológicas de Castillo e Frederico (2010) para operacionalização dessa discussão, propondo alguns temas principais, a saber: a atividade produtiva dominante, os agentes envolvidos, os seus círculos de cooperação, a logística, o uso e a gestão do território.

Em primeira instância, como a análise do circuito parte do produto, é importante identificar as atividades produtivas que regulam um determinado espaço, considerando os aspectos técnicos e normativos. Por conseguinte, deve-se reconhecer os principais agentes envolvidos, pois, assim como as etapas da produção estão dispersas, os agentes também nem sempre estarão na mesma localização geográfica, possuindo menor ou maior poder no regulamento do movimento. É fundamental entender o círculo de cooperação a partir dos agentes (empresa-empresa; empresa-poder público federal, regional, local, associações, universidades, organizações não governamentais etc.).

Outro fator relevante é a logística, atualmente compreendida como circulação corporativa caracterizada por um conjunto de competências operacionais, materiais e normativas (CASTILLO, 2011), que se desenvolve de forma arrebatadora e é essencial na articulação e no entendimento das diversas etapas do circuito espacial. Assim, possibilita a análise das condições físicas e o movimento dos fluxos que se entrecruzam. Essa ideia de logística difere da concepção disseminada no século XX, quando era definida como troca de informações confidenciais para promoção de parceiras e investimentos, o que era tido como o elemento diferencial do mercado globalizado, onde as disputas e a concorrência são cada vez mais acirradas. A sua dimensão e profundidade infraestrutural merece atenção especial, uma vez que, através dela, se perpetua a cooperação entre as diversas fases da produção.

Ainda se faz necessário identificar minuciosamente o uso e a gestão do território nas diversas etapas do circuito espacial produtivo, observando-se a regulação políticoadministrativa, o acesso e a mobilidade do território, o lócus das atividades produtivas, fruto de decisões corporativas sobre os atributos disponíveis (naturais e técnicos), a hierarquia urbana, a quantidade, a qualidade, a distribuição, os arranjos adjacentes envolvidos e a maneira como são usados. (CASTILLO, 2011). 
SILVA, F. O.; FERREIRA, W. R.

A logística urbana na produção do espaço

Partindo dessa proposta, ainda segundo Castillo, nos é permitido confrontar a configuração territorial pretérita e os atuais arranjos espaciais produtivos, tendo em conta o diagnóstico do papel do Poder Público, as cooperações e relações de conflito e a hierarquia entre os lugares, com suas diversidades temporais coexistentes. Podemos considerar esse confronto um embrião para o planejamento e para a gestão participativa (ou pelo menos ideal no que se refere aos interesses e demandas sociais) do território subutilizado pelos circuitos espaciais produtivos. Subutilizados, diga-se de passagem, porque, além de espaços produtivos, são também espaços sociais que escapam, de certa forma, da lógica dos circuitos.

Na medida em que a globalização intensifica a competição mundial e define, entre Poder Público e grandes corporações, os líderes dessa disputa, promove o (re) ordenamento territorial, impactando a política, a economia e a cultura da sociedade. Nesse contexto, a atuação do Poder Público e do empresariado no território brasileiro tem se pautado cada vez mais na racionalidade e na eficácia dos fluxos materiais, de modo que a moderna Logística surge como uma questão-chave na globalização.

\section{GLOBALIZAÇÃO: PRESSUPOSTOS CONCEITUAIS}

Ao longo do século XX ocorreram diversas mudanças no mundo, as quais foram consequências de grandes inovações tecnológicas e organizacionais, possibilitando o incremento e a propagação do capital, em razão de novas técnicas e movimentos de bens, pessoas, serviços e informações.

No Brasil, prevalecia, em meados de 1960, a integração vertical das indústrias com linhas de montagem e produção concentradas em áreas específicas, que hoje se denominam bairros industriais, como componentes que resistiram às mudanças na morfologia das nossas cidades. Mantinha-se a necessidade de extensas linhas de montagem e grandes volumes de estoques como parte da cadeia produtiva. Dessa forma, as indústrias buscavam e se instalavam sempre em áreas de economias de aglomeração ${ }^{8}$, isto é, áreas atrativas pela

\footnotetext{
${ }^{8}$ Economias de aglomeração consistem em ganhos de produtividade que são atribuídos à aglomeração geográfica das populações ou das atividades econômicas. "Como a fonte dos ganhos de produtividade se situa no exterior das empresas, no meio que as rodeia, fala-se de economias externas ou externalidades." (POLÈSE, 1998, p.77).
} 
SILVA, F. O; FERREIRA, W. R.

A logística urbana na produção do espaço

disponibilidade de mão de obra, infraestrutura, incentivos fiscais e, principalmente, pela acessibilidade e mobilidade para a distribuição dos produtos.

A partir da década de 1970, as características da produção industrial foram admitindo novos conceitos, em decorrência da evolução da ciência e das trocas, agora cada vez mais internacionais. De todas as mudanças podemos enumerar algumas que se destacaram: (1) inovação da logística de abastecimento e distribuição por meio de contêineres e transporte multimodal, o que possibilitou a produção just-in-time ${ }^{9}$; (2) constituição de alianças estratégicas que resultaram em grandes círculos de cooperação, agregando valores e agilidade às marcas hoje conhecidas mundialmente; (3) concepção de planejamento estratégico, que induziu a flexibilidade e capacidade das empresas de se sobressaírem diante das dificuldades impostas pelo mercado mundial; (4) terceirização de serviços que não gerassem lucros à empresa, o que motivou o surgimento de empresas "core competences", altamente especializadas em determinadas tarefas; (5) a inserção do código de barras e de outros recursos para acompanhamento de estoques e vendas, que antes eram geridos manualmente.

São essas as mais relevantes variações na produção industrial, que fizeram com que a economia do Brasil e de outros países subdesenvolvidos atuassem na retaguarda dos principais movimentos e ajustes das nações desenvolvidas. Com o cuidado em construir um espaço harmonioso e interpretativo, sobretudo no tocante às questões produtivas e à articulação dos agentes no território, temos, no final do século $\mathrm{XX}$, o desenvolvimento cumulativo das condições materiais, conferindo uma nova natureza ao espaço geográfico - o período técnico-científico-informacional ${ }^{11}$.

\footnotetext{
${ }^{9}$ Just in time é um sistema de administração da produção que determina que nada deve ser produzido, transportado ou comprado antes da hora certa. De acordo com Gianesi e Corrêa (1993, p. 44), o Just in Time surgiu no Japão, em meados da década de 70 , sendo o centro de sua criação e desenvolvimento a Toyota Motor Company. Esta, por sua vez, buscava um sistema de administração da produção que tivesse a capacidade de coordenar a produção de acordo com a demanda de diferentes modelos e cores de veículos e sem atraso.

${ }^{10} \mathrm{O}$ conceito de Core Competence (que, em português, poder ser traduzido por Competência Nuclear) surgiu pela primeira vez em 1990, na Harvard Business Review, num artigo intitulado "The Core Competence of the Corporation", da autoria de Gary Hamel e C. K. Prahalad (1990). Segundo os seus autores, Core Competence designa as competências estratégicas, únicas e distintivas de uma organização que conferem a ela uma vantagem competitiva intrínseca e, por isso, constituem os fatores chave de diferenciação face aos concorrentes.

${ }^{11} \mathrm{O}$ termo aparece em várias obras de Milton Santos. A primeira vez ele utiliza a expressão "meio técnicocientífico" é quando da publicação de seu livro Espaço \& Método (1985). Nessa época ainda não se tinha, de modo difundido e presente, o discurso da globalização. Contudo, é no livro A Natureza do Espaço: Técnica e Tempo, Razão e Emoção (1999) que esta noção é desenvolvida em sua forma mais acabada.
}

Revista Cerrados, Montes Claros/MG, v.16, n. 1, p. 159-182, jan./jun.-2018 
SILVA, F. O; FERREIRA, W. R.

A logística urbana na produção do espaço

Nesse momento de transição, Uberlândia foi a cidade mais propensa, no interior de Minas Gerais, à expansão da nova natureza atribuída ao espaço geográfico, dado sua localização, suas funções de entreposto comercial, sua capacidade de modernização e suas influências políticas. Tais características vão ao encontro da ideia de "configuração territorial" proposta por Santos (1993), que consiste na reunião dos sistemas naturais com os acréscimos feitos pelos homens nesses sistemas. Em outras palavras, a configuração territorial é formada pelo conjunto de aparelhos de engenharia que o homem vai superpondo à natureza, de maneira a permitir que se criem as condições de trabalho próprias de cada época.

Essas características garantiram a valorização e o reordenamento do espaço destinado à circulação, o que possibilitou a adequação do território uberlandense à modernização agropecuária e telecomunicativa, com a ampliação do complexo agroindustrial, o planejamento urbano aplicado aos transportes, a instalação de um polo universitário, a expansão e diversificação dos serviços terciários e as atividades de comércio varejista e atacadista. Por isso, chegou a ser denominada cidade logística do Brasil, o que permitiu que sua configuração territorial servisse de suporte para o desenvolvimento econômico do estado.

Uberlândia é a $2^{\mathrm{a}}$ economia no ranking de Minas Gerais, perdendo apenas para a capital, Belo Horizonte, e sua região metropolitana. Na economia do país, ocupa a $21^{\mathrm{a}}$ posição, com participação do PIB de 25774947 mil (IBGE, 2013). Também foi divulgado, na Revista Istoé (2015), um estudo feito pela consultoria Austin Rating, que analisou, classificou e mapeou o nível de desenvolvimento socioeconômico dos municípios brasileiros, apontando Uberlândia como a $8^{\mathrm{a}}$ melhor cidade do Brasil para se viver.

Paralelamente à instalação de infraestruturas públicas e privadas e às novas técnicas e sistemas de informação no Brasil, Uberlândia passou a consolidar suas redes de transporte, produção agroindustrial, comércio, serviços e informações, (re) construindo o território na tentativa de assegurar a sua fluidez, em resposta à densidade e dissolução do meio técnico-científico-informacional.

Diante dos impactos causados, a cadeia produtiva e a integração da economia extrapolaram as fronteiras regionais e locais rumo à lógica nacional. Quando se trata das megalópoles, brasileiras ou estrangeiras, fala-se na dilatação dos limites nacionais, atingindo a escala global. É o processo atual pelo qual passamos e que Santos (2000) chama de "globalização". Nesse contexto, torna-se cada vez mais necessária e comum a formação de redes de comércio, transportes, telecomunicações etc. entre as empresas fornecedoras, Revista Cerrados, Montes Claros/MG, v.16, n. 1, p. 159-182, jan./jun.-2018 
SILVA, F. O.; FERREIRA, W. R.

A logística urbana na produção do espaço

produtoras e distribuidoras que, apesar de situadas em locais, regiões e países dispersos, têm pelo menos um objetivo em comum: atender o mercado globalizado.

Conforme assinala Santos (2000), se tornou possível a convergência dos momentos: "o tempo real também autoriza usar o mesmo momento a partir de múltiplos lugares; e todos os lugares a partir de um só deles. E, em ambos os casos, de forma concatenada e eficaz". Assim, as atividades agroindustriais, de serviços e comércio formam complexas cadeias produtivas em escala mundial, gerando os circuitos espaciais produtivos que, por sua vez, são dependentes da Logística. Esta última, obviamente, é um dos elos mais importantes do sistema produtivo, pois tem a capacidade de exigir técnicas modernas para o acondicionamento, o manuseio, a estocagem, a distribuição e a circulação.

Longe de esclarecer as forças que modelam o mundo, o conceito de globalização desempenha outras funções bem diferentes daquelas com as quais estamos acostumados. Aqui o termo é compreendido como "discurso conveniente" que ajuda a legitimar e justificar o projeto neoliberal do capitalismo, funcionando como um recurso através do qual os agentes das grandes corporações e do Poder Público disciplinam a sociedade e ditam seus interesses.

$\mathrm{Na}$ forma como se expõe a globalização - perversa, veloz, intuitiva e de multialcance - vemos um projeto totalizador. No entanto, deve-se ressaltar que as técnicas capazes de dissolver territórios e referências identitárias e culturais não estão disponíveis a todos, ou pelo menos não podem ser utilizadas por qualquer sujeito, em qualquer lugar e tempo.

O espaço tornou-se fluido, o tempo sofreu compressão. Mas nem todos são fluidos. Se o mundo nesse início do século XXI é marcado pela fluidez, pela velocidade, são muitos os lugares e regiões que ainda são lentos e que não conseguem atender às exigências desse tempo (TRINDADE, 2010, p.47).

Reduzir a globalização a esse discurso estruturalista é um equívoco, na medida em que descaracteriza o processo, impossibilitando a compreensão da complexidade de sua participação na ordem mundial. Uma análise sobre a globalização deve partir, primeiramente, do reconhecimento de seu aspecto totalitário, dissecando suas formas de poder socioeconômico, cultural e político, suas forças (mensuradas ou não, profundas ou rasas). Cada variável tem o seu papel e alcance. É claro que nem todos encaram a globalização como nociva à humanidade; ao tempo que alguns a satanizam, outros se mobilizam por ela e a aclamam como solução para grande parte dos problemas do mundo. 
SILVA, F. O.; FERREIRA, W. R.

A logística urbana na produção do espaço

Na Conferência da Organização Mundial do Comércio (OMC), realizada em Seattle (EUA) em dezembro de 1999, uma manifestação interrompeu os acordos internacionais, gerando uma série de conflitos entre os manifestantes e a polícia em razão da instabilidade de emprego, da exploração do meio ambiente e da injustiça social. Em síntese, temia-se a globalização e seus efeitos sobre as pessoas. Tais temores não diminuíram; ao contrário: daí em diante, cada vez mais grupos "antiglobalização" têm aumentado em tamanho e força.

Em outro extremo, premiado pelo Nobel $^{12}$ em Economia de 1998, Amartya Sen defendia que a globalização "deu uma grande contribuição científica e cultural ao mundo, além de beneficiar a muitos em sentido econômico". O Relatório de Desenvolvimento Humano de 1999 (ONU, 1999) corroborou essa ideia, afirmando que a globalização "oferece um enorme potencial para erradicar a pobreza no século XXI". Tais fundamentos otimistas são baseados na melhoria significante das condições socioeconômicas das famílias, considerando a nova classe média, que, no Brasil, significa um total de 104 milhões de habitantes, representando 53\% da população (EXAME, 2012).

O período de globalização pode ser visto como "espírito do capitalismo" ou como a própria evolução do sistema capitalista, dependendo das identidades culturais, políticas, sociais e econômicas de quem se arriscar a compreendê-lo. Aqui não vamos confundir "espírito" com o resultado de tendências econômicas históricas que se combinaram em meio a articulações de poder e disputa pelo mercado, fazendo com que os processos de exploração e dominação, sempre presentes na história da humanidade, fossem essencialmente mobilizados em favor de determinadas forças empresariais e detrimento de outros grupos sociais.

A noção de velocidade do tempo, associada às inúmeras possibilidades de vencer as distâncias que continuam existindo no espaço, emerge na globalização com algumas promessas: maior rapidez nos fluxos de capitais, bens, mercadorias, pessoas e informações; maior facilidade de comércio internacional; grande disponibilidade de produtos e preços; transferência tecnológica; incremento de novas técnicas, serviços e, consequentemente, de empregos; abrandamento das relações entre os países; inovação tecnológica a serviço da

\footnotetext{
${ }^{12}$ Amartya Sen recebeu o Prémio Sveriges Riksbank de Ciências Económicas, em Memória de Alfred Nobel, em 1998, pelas suas contribuições para a economia do bem-estar, entre outras ações nos países em desenvolvimento.
} 
SILVA, F. O.; FERREIRA, W. R.

A logística urbana na produção do espaço

saúde, educação e do meio ambiente; diversidade cultural; investimentos em infraestruturas; etc.

Os agentes centrais da globalização são incontestavelmente as grandes corporações, que atuam em escala mundial, e o Poder Público, que detém os poderes judiciários, legislativos e executivos em escala nacional, estadual ou municipal, tendo como atribuição governar e administrar os interesses públicos, cumprindo fielmente as ordenações legais. As corporações têm se aproveitado da ineficiência do Poder Público ou mesmo pagado por ela e se sentem à vontade para buscar oportunidades, alternativas just-in-time e estratégias territoriais que visem o lucro e os interesses individuais. Enquanto isso, o Poder Público, que pelo menos deveria mediar e acompanhar tais dinâmicas, finaliza seu papel com medidas paliativas quando tenta controlar os impactos causados pelas decisões corporativas. Em suma, é a globalização que contribui de forma significativa para o aceleramento e expansão das corporações, fortalecendo e disseminando sua presença no mundo.

Em 1985, o estrategista e desenvolvedor empresarial Kenichi Ohmae introduziu o conceito de "Tríade", ao mencionar um espaço global de mercado composto por EUA, Japão e Europa, países caracterizados como núcleos da globalização. No entanto, essa percepção já não é equivalente à contemporaneidade, pois novos agentes, como a China e a Índia, têm provocado mudanças expressivas na economia mundial, o que nos leva a concluir que as grandes corporações da chamada "Tríade" estão hoje submetidas à própria dinâmica que elas criaram.

Os novos agentes citados adquiriram experiências através das desvantagens impostas a eles e desenvolveram competências específicas que, aliadas à "desvantagem" dos custos de produção mais baixos, os colocaram em situação de emancipação e autonomia no mercado global. Esses países emergentes introduzem novas dinâmicas competitivas, às quais, em escala menor, várias empresas não conseguem se adaptar, criando outras condições de adaptação e remodelamento dentro da lógica de acumulação e concentração capitalista.

A espacialidade e profundidade da globalização, com o aumento das disparidades sociais, econômicas, culturais e ambientais no interior dos espaços, não é distante do cotidiano. A aceleração é cada vez maior, a comunhão entre telecomunicação e informática tem alterado tanto o tempo econômico, quanto o social. Em consequência, a sociedade criou a necessidade imediata de se manter on-line em diversos lugares no mesmo momento (seja pelo 
SILVA, F. O.; FERREIRA, W. R.

A logística urbana na produção do espaço

celular, pelo notebook, tablet ou por outros meios), exigindo uma resposta simultânea e sem barreiras; isto é, a Logística se tornou um imperativo.

\section{CONSIDERAÇÕES FINAIS}

Nesse contexto a Logística se insere como um elemento estratégico constitutivo da nova realidade espacial, procurando dotar os circuitos espaciais de produção e circulação de maior racionalidade organizacional e fluidez. Assim, é notório o interesse de uma parcela de geográfos por esse assunto, já que as infraestururas de transportes - os fixos (terminais e vias), suas redes (rodoviárias, aeroviárias, ferroviárias, dutoviárias e aquaviárias) - e seus fluxos imateriais ocupam lugar e tempo importantes no espaço e constituem a base de um sistema complexo. E a Logística Urbana de Cargas é um desmembramento específico que oferece suporte para comprender tal sistema.

Em uma macroeconomia em que a velocidade e as especificidades do produto têm vasta relevância, bem como a capacidade de conjugar o tempo, distribuir espaços de produção e abastecimento no quadro da cadeia de suprimentos (supply chains), a Logística evolui, tornando-se alicerce central na geração de vantagens competitivas.

Diante dos desafios que permeiam a análise e resolução dos problemas locais de ordem ambiental e operacional-econômica, resultantes de modelos já saturados, cabe à Geografia indagar as relações da sociedade no território, redefinindo e aproveitando as novas tendências para explorar as possibilidades de combinação de competências, através de parcerias entre o Poder Público e o Poder Privado. As respostas passarão, em boa medida, pela cooperação e conjugação de conhecimentos, de modo que o determinismo geográfico se mostra pouco proveitoso. Dessa forma, viabiliza-se reforça-se a capacidade de conceber o bem-estar social e de vivê-lo em alguma escala.

\section{REFERÊNCIAS}

ARROYO, M. Circuitos espaciais de produção industrial e fluxos internacionais de mercadorias na dinâmica territorial do estado de São Paulo. Boletim Campineiro de Geografia, Campinas, v. 2, n. 1, p. 07-26, fev, 2012.

BOMTEMPO, D. C. Dinâmica territorial, atividade industrial e cidade média: as interações espaciais e os circuitos espaciais da produção das indústrias alimentícias de 
SILVA, F. O.; FERREIRA, W. R.

A logística urbana na produção do espaço

consumo final instaladas na cidade de Marília - SP. 2011. 455f. Tese (Doutorado em Geografia), PPGG/UNESP/Presidente Prudente, 2011.

BOTELHO, R. E. P. O circuito espacial de produção e os círculos de cooperação da soja no Maranhão no período técnico-científico-informacional. 2010. 220 f. Dissertação (Mestrado em Dinâmica e Reestruturação do Território) - Universidade Federal do Rio Grande do Norte, Natal, 2010.

CASTElls, M. A Sociedade em Rede. 7. ed. São Paulo: Editora Paz e Terra, 2003.

CASTILLO, R. A. Agricultura globalizada e logística nos cerrados brasileiros, in SILVEIRA, Márcio Rogério (org.). Circulação, transportes e logística. São Paulo: Outras Expressões, 2011, p.331-54.

CASTILLO, R. Transporte e logística de granéis sólidos agrícolas: componentes estruturais do novo sistema de movimentos do território brasileiro. Investigaciones Geográficas, Boletin del Instituto de Geografia, UNAM, México-DF, n. 55, 2004.

CASTILLO, R.; FREDERICO, S. Espaço geográfico, produção e movimento: uma reflexão sobre o conceito de circuito espacial produtivo. In: Sociedade e Natureza. Uberlândia, v. 22, n. 3, p. 461-474, dez, 2010.

CHRISTALLER, W. Central places in Southern Germany. Prentice-Hall/ Englewood Cliffs, 1966. 230p.

CORRÊA, R. L. O espaço geográfico: algumas considerações. In: SANTOS, Milton (org.). Novos rumos da geografia brasileira. São Paulo: Hucitec, 1982.

EXAME, Revista. Mais da metade dos Brasileiros está na classe média. Disponível em: < http://exame.abril.com.br/brasil/noticias/mais-da-metade-dos-brasileiros-estao-na-classemedia> Acesso em 10 de março de 2016.

HAESBAERT, R. Territórios alternativos. São Paulo: Contexto, 2002.

HARVEY, D. A produção capitalista do espaço. $2^{a}$ ed. São Paulo, Annablume, 2006.

O espaço como palavra-chave. In: Revista GEOgraphia. Rio de Janeiro: UFF, v. 14, n. 28, p. 8 - 39, 2002.

ISARD, Walter. Location and space-economy. Cambridge: MIT Press, 1956.

LEFEBVRE, H. A produção do espaço. Trad. Doralice Barros Pereira e Sérgio Martins. Do original: La production de l'espace. 4e éd. Paris: Éditions Anthropos, 1991.

MARX, K. Grundrisse: Manuscritos econômicos de 1857-1858. Esboços da crítica à economia política. São Paulo: Boitempo, 2011. 
SILVA, F. O.; FERREIRA, W. R.

A logística urbana na produção do espaço

MORAES, A. C. R. de. Los circuitos espaciales de la producción y los círculos de cooperación em el espacio. In: YANES, L. et al. (Org.), Aportes para el estúdio del espacio socioeconômico, tomo III, El Colóquio. Buenos Aires: [s.n.], 1985.

MOREIRA, R. Repensando a Geografia. In: SANTOS, Milton (org). Novos rumos da geografia brasileira. São Paulo: Hucitec, 1982.

MYRDAL, G. Teoria econômica e regiões subdesenvolvidas. Rio de Janeiro: Saga, 1968.

ONU, Organização das Nações Unidas. Relatório do Desenvolvimento Humano 1999. Programa das Nações Unidas para o Desenvolvimento (PNUD). Lisboa: Trinova, 1999. 262p.

PERROUX, F. A economia do século XX. Porto: Herder, 1949/1967. 755p.

POLÉSE, M. Economia urbana e regional: lógica espacial das transformações econômicas. Coimbra: APDR, 1998.

PONS, J. M. S.; REYNÉS, M. R. M. Geografía de los transportes. Universitat de les Illes Balears, 2004.

RAFFESTIN, C. Por uma Geografia do Poder. França. São Paulo: Ática, 1993.

SANTOS, M. O espaço dividido: os dois circuitos da economia urbana nos países subdesenvolvidos. In: O espaço dividido. São Paulo: Edusp, 2004.

subdesenvolvidos. In: O espaço dividido. São Paulo: Edusp, 2004.

. Por uma Geografia Nova. São Paulo: Edusp, 2002.

Hucitec, 1999.

A natureza do espaço: técnica, tempo, razão e emoção. 3 ed. São Paulo:

SILVEIRA, M. R. Geografia da circulação, transportes e logística: construção epistemológica e perspectivas. In: SILVEIRA, Márcio Rogério (Org.). Circulação, transportes e logística: diferentes perspectivas. São Paulo: Outras Impressões, 2011. p.21-69.

TAAFE, J.; GAUTIER, J. R. Geography of Transportation, Fondations of Economic Geography Series. Prentice Hall, USA. 1973.

TRINDADE, G. A. Globalização, Redes e relação mundo-lugar: insistindo em um debate ainda não esgotado na Geografia. Geonordeste (UFS), v. 2, p. 13-36, 2010.

WEBER, A. Theory of the Location of Industries. 1a ed. Chicago: University of Chicago, 1929. 
Fander de Oliveira Silva - Possui Graduação e Mestrado em Geografia, ambos cursados pela Universidade Federal de Uberlândia (UFU). Atualmente é Doutorando pelo Programa de PósGraduação em Geografia da Universidade Federal de Uberlândia (UFU).

William Rodrigues Ferreira - Possui Graduação em Geografia pela Universidade Federal de Uberlândia; Mestrado em Engenharia do Transporte pela Universidade de Brasília (UnB) e Doutorado em Geografia Humana pela Universidade de São Paulo (USP). Atualmente é Professor do Programa de Pós-Graduação em Geografia da Universidade Federal de Uberlândia (UFU).

Artigo recebido em: 04 de março de 2018. Artigo aceito em: 03 de junho de 2018. Artigo publicado em: 30 de junho de 2018. 